\section{Ruralidad, conservación y justicia territorial. Legitimidades desiguales en la Patagonia Norte chilena*}

Rurality, conservation and territorial justice. Unequal legitimacies in Chilean Northern Patagonia

\author{
Juan Carlos Rodríguez-Torrent ${ }^{* *}$ \\ FERnando ManduJano-Bustamante ${ }^{* \star *}$ \\ RodRIGo VARGAS-CALLEGARI ${ }^{* *+*}$
}

\section{Resumen}

En este artículo planteamos y discutimos que la refrescante notoriedad que ha alcanzado la Patagonia en las últimas tres décadas, está asociada a los nuevos lugares de enunciación que la describen en lo que ella contiene y puede proyectar. Nuestra tesis es que narrativamente se instala por parte de los ambientalistas conservacionistas una diferencia radical entre precio y valor, que permite transmitir simbólicamente, y con mucha fuerza, una figura espacial y territorial antidesarrollista, la que se aloja internacionalmente como sentido y conciencia del valor simbólico de los ecosistemas, de la posición de los humanos y los demás seres en la preservación de la vida. Sin embargo, esta expansiva "opción verde" o de "clave eco" opera también como limitación de oportunidades, litigando con la memoria ganadera tradicional que requiere de grandes extensiones para la reproducción de las unidades familiares, las que ven imposibilitadas de acceso a fuentes básicas de recursos como las praderas y el bosque. De este modo, la supervivencia de la ruralidad tradicional está fuertemente cuestionada debido a la pérdida de soberanía por la intromisión de diversos y contradictorios imaginarios territoriales, así también de las políticas generales del Estado neoliberal y los gobiernos locales, configurando un nuevo mapa territorial en permanente tensión.

Palabras claves: Patagonia, territorio, ruralidad, conservación, justicia territorial.

\begin{abstract}
In this article, we propose and discuss that the refreshing notoriety that the Patagonia has
\end{abstract}


reached in the last three decades is associated with the new places of enunciation that describe it in what it contains and can project. Our thesis is that a radical difference between price and value is installed on the part of environmental conservationists. This difference allows transmitting symbolically and with great force an anti-developmental spatial and territorial figure, which is lodged internationally as meaning and awareness of the symbolic value of ecosystems and the position of humans and other beings in the preservation of life. However, this expansive "green option" or "eco key" also operates as a limitation of opportunities, litigating with the traditional livestock memory that requires large areas for the reproduction of family units, which are unable to access basic resources such as the grasslands and the forest. In this way, the survival of traditional rurality is strongly questioned due to the loss of sovereignty caused by the intrusion of diverse and contradictory territorial imaginaries and the general policies of the neoliberal State and local governments, configuring a new territorial map in permanent tension.

Key words: Patagonia, territory, rurality, conservation, territorial justice.

\section{Introducción}

La zona norte de la Patagonia occidental corresponde al área de influencia directa de la Carretera Austral (Ruta 7) e incluye la provincia de Palena más la región de Aysén. Un territorio casi un $20 \%$ más extenso que Islandia, pero con menos de un tercio de su población. Años de estudio de terreno y reflexión permiten presentar la Patagonia occidental, y en especial su área norte, como un territorio que pone a prueba o desafía esquemas teóricos de ordenamiento territorial (Boisier, 1998; Wong-González, 2010), de territorialización (Sack 1986; Haesbaert 2013), de geometría del poder (Massey 2005), de política y administración del Estado (Pierson 2004), de alternativas de desarrollo sostenible (Patterson 2015), de construcción de la sociedad civil, de supervivencia cultural local.

El tema de este artículo es la presentación y análisis de las particularidades de esta zona que la convierten en una frontera interior. La magnificencia de la naturaleza que exhibe es inversamente proporcional a la precariedad de su desarrollo económico urbano y rural, de su autonomía política, de su identidad productiva y desarrollo cultural. La hipótesis que sustenta el análisis es que la Patagonia norte ha sido incorporada al territorio nacional en forma tal, que los lazos políticos, económicos y sociales en base a los cuales se estructura esa vinculación conducen a perpetuar la falta de autonomía. Se trata de una relación perversa, donde el centralismo y autoreferencialidad del poder central en Santiago, constituye sólo uno de los factores.

El espacio y el territorio en la Patagonia se han organizado y se ha vivido como una frontera interior por parte de sus habitantes rurales $y$ urbanos. Al no existir continuidad territorial con el Chile centro-sur, se ha generado una alta diferenciación estructural y subjetiva que ha condicionado las percepciones y la experiencia1.

\footnotetext{
La conectividad inconclusa, sumada a la distancia y el aislamiento han propiciado que el Estado trate a este territorio como una zona insular: no hay carreteras (continuas), no hay ferrocarril, no hay líneas de transmisión de energía (ductos de petróleo o gas, tendido eléctrico) que una el territorio al resto del país, como los hay entre otras regiones de Chile. Ningún esfuerzo del Estado ha sido suficiente para romper esa insularidad, de hecho los medios de transporte más importantes desde comienzos del siglo XX son el barco y el avión.
} 
En lo fundamental: porque "lo nacional" solo puede existir en la medida que se experimenta comouna "vivencia", es decir, comouna presencia rutinizada en la cotidianeidad ${ }^{2}$ (i.e. servicios) (Ortiz 2005). De ahí que, en este caso dominado por la baja integración estatal -siguiendo a Doreen Massey (2005)-, lo social y lo espacial deban ser conceptualizados conjuntamente, porque lo que se vive cotidianamente en el plano local no es independiente, es en función de la construcción del espacio nacional y regional; porque "lo local es siempre un nodo abierto de relaciones, una articulación, un entramado de flujos, influencias, intercambios" (2005:79). Es decir, localmente hay un interjuego de influencias, dominación y subordinaciones que establecen y modifican la "geografía de los vínculos y contactos" (op. cit.), cristalizando las variaciones históricas del trabajo como espacio generativo de lo múltiple en la multiplicidad.

Entonces, se desprende que la ciudad de Coyhaique dentro de esta vida insular sea el principal centro político y administrativo, de servicios y comercio a nivel regional, y simultáneamente periferia nacional. De este modo, los demás poblados son periferias subordinadas de la capital regional de Aysén. $\mathrm{Y}$, en forma paralela, las reflexiones derivadas

En este punto reconocemos tres cuestiones históricas asociadas a la Patagonia chilena, y en particular en el caso de Aysén: 1) no hubo una ocupación territorial precedida por presencia oficial como en el resto de Chile, como ocurrió con las tierras agrícolas de la zona central y el desarrollo de la minería en el norte, instaurándose una fórmula predominantemente privada (Martinic 2014:415); 2) la existencia de un régimen político de carácter unitario y centralista, que incorpora tardíamente las tierras y poblaciones australes al imaginario político, económico y simbólico del Estado-nación, ya que en un esquema centro-periferia no fueron consideradas aptas para el desarrollo; 3) que estas condiciones de anexión, propician en la población rural características de vida autónomas (bottomup) y con pocas posibilidades de imaginar un futuro distinto al de la reproducción simple, de acuerdo a infraestructuras viales y de transporte disponibles, y de los limitados servicios territorializados provistos por el Estado. de esta conceptualización deben orientarse hacia los efectos de estos flujos entendidos como elecciones y decisiones, porque el poder transformador, estabilizador y diferenciador de cada localidad está en las variaciones de los flujos. Es decir, la reflexión no es solo sobre la contingencia en la perspectiva de lo globallocal; sino que lo es también sobre la presencia y el papel del Estado: sobre el abandono, los caminos, los servicios, la conectividad, la alimentación y la visibilidad alcanzada a través de sus atributos.

La dependencia política de la Patagonia de los poderes centrales, como también a la administración de turno en el Poder Ejecutivo, se sustenta no sólo en normas, decretos y leyes que regulan el funcionamiento de las instituciones públicas, sino que además es reforzada por tres mecanismos: la designación central de las autoridades locales, el control central de contratación y subsidio para el desempeño de funcionarios y profesionales, y la mínima autonomía local para decidir el gasto público. A la vez, esos representantes locales cuentan con el servicio de una red de profesionales y funcionarios, que desde su contratación tienen dependencia directa e indirecta de ellos o de ministerios del gobierno central y que además son remunerados con subsidios y asignaciones de zona fiscales. Por lo tanto, el dominio central determina también la gran parte del capital humano que se desempeña en la zona ${ }^{3}$.

Hasta el día de hoy las provincias y regiones de Chile no pueden elegir sus propias autoridades de gobierno. Éstas son designadas, son cargos de confianza del gobierno central. Por lo tanto el Intendente regional y los gobernadores provinciales de la Patagonia asumen con un conflicto de roles esencial: administran y representan metafóricamente el territorio colonial, pero deben, al mismo tiempo, lealtad a la corona. Si del gobierno central se duda de su lealtad, se acaba su poder. 
Asimismo, si apenas un $12 \%$ de la inversión pública es administrada en los gobiernos locales de Chile contra una media de $55 \%$ de los países de la OCDE, y - a la vez - gran parte de las autoridades y profesionales que deciden al respecto en la Patagonia, deben obediencia al gobierno central, el margen de poder local en este territorio es básicamente marginal y residual, diría Massey (2005).

Mapa 1: Patagonia Aysén y Patagonia Palena.

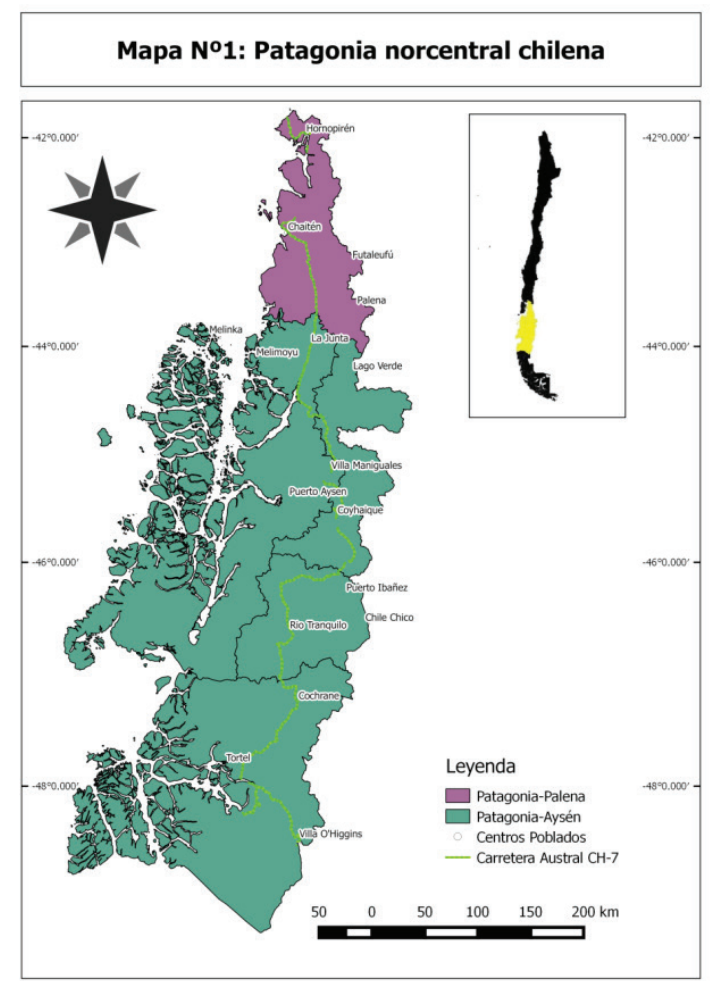

Fuente: Elaborado por Juan Saénz Passeron.
La insularidad producida por el Estado sobre la Patagonia, cuenta con una importante carga semántica asociada a un simbolismo primigenio construido por exploradores y navegantes, científicos como Darwin e historiadores canónicos como Vicuña Mackenna, los que prefiguran una personificación territorial que no descansa en la idea de paraíso o de la belleza (ver Facchineti et al. 1997). Entre las adjetivaciones "creadas y rescatadas" que crean la anatomía de una imagen desfavorable, se habla de terrenos áridos, sin valor alguno, desiertos estériles, yermo completamente uniforme; paralelamente: selvática y horrible, de frío glacial, vientos implacables, paisaje melancólico y horrendo (op.cit. 44-46).

Por ser consideradas primero terra nullius y luego "tierras lejanas" y de "difícil acceso", que no constituyeron primera prioridad material desde el punto de vista de su poblamiento y dotación de servicios, y con grandes dificultades para la asimilación de la nacionalidad en el plano simbólico de sus habitantes, la colonización inducida se constituyó sobre la base de entrega de grandes extensiones de tierra a la Sociedad Explotadora de Aysén y la Compañía Río Baker, así como a familias santiaguinas. Mateo Martinic (2014: 222-223) entrega importante relación de las concesiones fundiarias a particulares en 1903, detallando extensiones que van entre las 15.000 y 1.000 .000 de hectáreas, las que finalmente dan forma al territorio. Las empresas no pudieron cumplir con objetivos de creación de infraestructuras (i.e. transporte fluvial interior) y colonización ${ }^{4}$, que además tenía por objetivo

Se trataba de poblar con más de mil colonos, y desarrollar una industria principalmente ovina y bovina, con fin de obtención de carnes, lana, grasa y cueros. Ello implicaba la tarea titánica de rozar el bosque en las tierras adjudicadas y construir un puerto en el Pacífico, porque la masa ganadera de Aysén aumentaba sin tener mercado interno. Sin embargo, el fracaso se explica porque el 
acercar la producción ganadera argentina al Pacífico, ya que "los funcionarios del Estado sobreestimaron la capacidad de los suelos, que en su gran mayoría eran de uso forestal y no ganadero, de lo cual se dieron cuenta después de quemar grandes superficies" (Otero 2006:109).

Los efectos de esta negligente ocupación fueron desastrosos, produciendo una erosión irrecuperable y la vulnerabilidad de fauna endémica, la que fue llevada al límite casi de su desaparición. En una extensión de entre 50 y 60 kilómetros entre mar y cordillera, millones de toneladas de cenizas, lodos y tierra fueron arrastradas por las lluvias, cubriendo causes o llevadas al mar (op. cit. 125-127). Esta condición generó un paisaje irregular y de contrastes que se mantiene hasta hoy: tierras erosionadas y tierras vírgenes; bosques desaparecidos y bosques milenarios; campos abandonados y campos productivos.

Las condiciones residuales y recursivas de esta experiencia territorial construida por la presencia de privados y el Estado, en las últimas dos décadas han sido objeto de producciones discursivas y de conflictos materiales e ideológicos asociados a los recursos disponibles y sus posibles usos dentro de una globalización neoliberal. Esto, porque en la región de Aysén existen recursos de alto valor ${ }^{5}$ que generan propuestas encontradas, donde el $50 \%$ de las tierras están sometidas al régimen del Sistema

Estado no invirtió en infraestructura y se encontraba alejado de los centros de consumo (Otero 2006: 109-110; Martinic, 2014: 240-241).

5 En los Campos de Hielo Sur y Norte se encuentran las terceras reservas de agua dulce a nivel mundial, así como el caudal de algunos ríos como el Pascua y Baker tienen un potencial incalculable para la producción de hidroelectricidad.
Nacional de Áreas Protegidas del Estado 6 (SNASPE), a lo que se suman las iniciativas de conservación privadas.

Las más emblemáticas propuestas privadas están asociadas al fallecido ambientalista y filántropo Douglas Tompkins, cuya experiencia juvenil como viajero en la década de los años 60's, y luego como empresario, le permitió forjar una diferencia radical entre valor y precio, entre un bosque y la agricultura industrial, entre una presa y un río de flujo libre. Harto de la historia oficial y del destino del "desarrollo", a través de sus fundaciones comenzó con la compra de tierras en la Patagonia, destacando su proyecto Parque Pumalin (290.000 hectáreas), y a partir de la compra de la Estancia Valle Chacabuco y otras tierras aledañas (80.937 hectáreas), se propuso desarrollar el futuro Parque Patagonia (292.183 hectáreas). A su muerte inesperada, expresando su deseo, su viuda Kristine Mc Divitt, hizo la donación más grande tierras privadas al Estado de Chile: 407.625 hectáreas. La única exigencia, es que éstas pasaran a la categoría de Parques Nacionales; y que en reciprocidad a esta donación, el Estado comprometiera pasar a un régimen de protección unas 900.000 hectáreas más, que son de propiedad fiscal ${ }^{7}$.

Se trata de figuras legales como Parques Nacionales, Reservas o Monumentos Naturales. Los Parques Nacionales y sus dimensiones expresadas en hectáreas son: Queulat (154.093), Isla Guamblin (10.625), Isla Magdalena (157.616), Laguna San Rafael (1.742.000). Las reservas corresponden a: Lago Carlota (18.060), Lago Las Torres (16.516), Lago Rosselot (12.725), Las Guaitecas (1.097.975), Río Simpson (41.621), Coyhaique (2.150), Trapananda (2.305), Cerro Castillo (179.550), Lago Jeinimeni (161.100), Lago Cochrane (8.361) y Katalalixar (674.500). Los monumentos naturales son: Cinco Hermanas (228) y Dos Lagunas (181)

Independientemente de los beneficios ecológicos y patrimoniales netos para la zona, y el planeta entero, en un escenario de calentamiento global, el evento repite la situación del territorio como un espacio marginal en la geografía del poder. En la elección presidencial reciente, la zona representó apenas 0,6\% del total de votos válidos del país (SERVEL 2018). 
A fines de enero del 2018, la Presidenta de la República Michelle Bachelet acompañada por la viuda firmó el decreto de creación de la Red de Parques Nacionales de la Patagonia, que amplía significativamente la superficie de dos parques ya existentes e incorpora tres nuevos: el Pumalín, el Melimoyu y el Patagonia, sumando una superficie total de 4,5 millones de hectáreas en la zona ${ }^{8}$ (Gobierno de Chile 2018). La noticia impacta, pues es un gran esfuerzo público y privado por la preservación ambiental y patrimonio natural del territorio, por lo que el evento ocupó destacadas columnas de la prensa chilena e internacional. No obstante, aparecieron voces de autoridades locales - entre ellos dos alcaldes y un diputado - reclamando por qué en la decisión no hubo participación de la población local.

Uno de los argumentos que repiten los detractores de la iniciativa, es que la conversión de territorios en parques los convierte en lugares prohibidos para emprendimientos de los lugareños que no sean sólo turísticos: "crean una red de parques, crean una red de prohibiciones", "nunca nos preguntaron qué tipo de desarrollo queríamos". La imagen transmitida en los medios, donde la Presidenta firma el decreto sin la compañía de población ni autoridades de la zona, parece sugerir en forma visual que la iniciativa no surgió ni se desarrolló desde el territorio. Además, una definición tan importante y angular tampoco aparece en las publicaciones de planes estratégicos vigentes de la región: no figura ni implícitamente en la Estrategia Regional de Desarrollo de Aysén 2009-2030 (Gobierno de Chile-ILPES- CEPAL

Ver: Gobierno de Chile (2018) http://www.gob.cl/la-red-parquesla-patagonia-suma-45-millones-hectareas-protegidas-chile/

9 Ver: El Mercurio 28 de enero 2018.
2009), como tampoco en el Plan Especial de Desarrollo de Zonas Extremas (PEZDE Aysén 2018), el Plan Regional de Ordenamiento Territorial de Aysén (2009).

Con sus adquisiciones, la reimaginación y desideratum del territorio por parte de Tompkins, transforma su objetivo en una relación de poder. La ambición por la preservación -sustentada en los principios de la ecología profundatransforma al territorio en una macrozona ambientalmente de valor incalculable. Esto hace que el paisaje se imponga por sí mismo y que se naturalice en la opinión pública un dispositivo narrativo sobre "lo verde" como contención, que permite que inclusive el propio capitalismo aparezca como conservacionista al poner límite a actividades extractivas y ganaderas, para afianzar figuras ligadas a la generación de rentas como el turismo exclusivo o el descanso y la contemplación. De este modo, al adicionar las tierras del Estado y las privadas, por una parte, se trata de mantener la región en condición efectivamente virgen (en lo que queda); por otra, que los usos múltiples del territorio puedan ser un reflejo imitativo de los procesos naturales.

Así, el dispositivo de la conservación como un objetivo íntimo y de ambición planetaria, opera como una nueva representación del espacio, como expresión de valores y manifestación de ideologías, que implica y justifica cambios en base a operaciones económicas diversas, y que determinan discursos en el campo de la producción cultural. De este modo, pensar como un bosque, donde todos los individuos son necesarios, inclusive los árboles muertos, constituye un campo de fuerza que disputa su hegemonía frente a los cuerpos en movimiento de las poblaciones locales que buscan su reproducción, que son las que han expresado 
conexiones en el espacio, instaurado límites, elegido, priorizado y nombrado en un proceso diacrónico, conectando la memoria y la biografía (Ingold 2000) como ontología relacional. También, un enfrentamiento con imaginarios extractivistas, mineros y energéticos.

Esto mismo hace que el ideal antropológico del aislamiento etnográfico, se encuentre hoy mediado por fuerzas de cambio y poder estructurante sobre la espacialidad, y que lo importante sean los procesos de diferenciación territorializados producto de cómo se apropia y vive esta singularidad devenida del flujo.

Podríamos indicar que dentro de las cuestiones más relevantes en esta construcción discursiva y que propicia legitimidades diferenciadas para desarrollar los propios objetivos, se ubican las siguientes: 1) las áreas protegidas por parte del Estado bajo la figura de parques nacionales, reservas o monumentos nacionales; 2) la participación de privados (chilenos y extranjeros) en la compra de tierras con fines de protección ambiental, negocios diversos (lodges, casas de descanso, venta de bonos de carbono) o especulación, y que implica el desarrollo de un mercado en expansión; 3) una larga discusión -ambiental, política y de opinión públicasobre la construcción de cinco represas para la producción de hidroelectricidad por parte de la transnacional ENDESA, con muchos grupos e intereses litigantes que potenciaron la geomarca Patagonia $\left.{ }^{10} ; \mathrm{y}, 4\right)$ producto de

10 La idea de "geomarca" apunta al valor alcanzado por el territorio y el paisaje a través de sus atributos, reconocido mediante un conjunto de geosímbolos (ríos, lagos, cerros, flora y fauna) proyectados en distintos formatos como folletería, videos promocionales, páginas de internet y productos, que en este caso hablan de belleza y pureza natural, conservación y buenas prácticas, de exclusividad y anonimato, que invitan a activar el deseo de conocer y tener fundamentalmente experiencias en grandes territorios abiertos (ver Rodríguez et al. 2014). lo anterior, el decantamiento de un discurso ambiental proteccionista como una nueva clave ciudadana, siendo de amplio espectro social y territorial nacional e internacional.

De lo enumerado, se desprende problemáticamente cómo son integradas y expresadas las diferencias al interior de la región, las diversas y múltiples trayectorias que puede tener el espacio como reflejo de la sociedad, sus poderes y posiciones, ya que -como sostiene Roseberry (2014)- son diversas las formas de incorporación al sistema, los posicionamientos específicos ocupados y los papeles desempeñados, como resultado de las diferentes luchas. De este modo, hemos dividido el texto en cinco apartados, con el fin de contemporaneizar la ruralidad patagónica: 1) las marcas en el territorio; 2) las nuevas configuraciones territoriales; 3) la gobernanza; 4) el debilitamiento de la producción ganadera; y, 5) los vivientes.

Fotografía 1: publicidad de grupos ambientalistas, en el que se aprecia en un primer plano el rostro de una mujer herida por agresión, con tendido eléctrico de alta tensión a sus espaldas y atrás los montes nevados. Se interroga: ¿qué salvaje haría esto?, en alusión a la potencial destrucción ambiental.

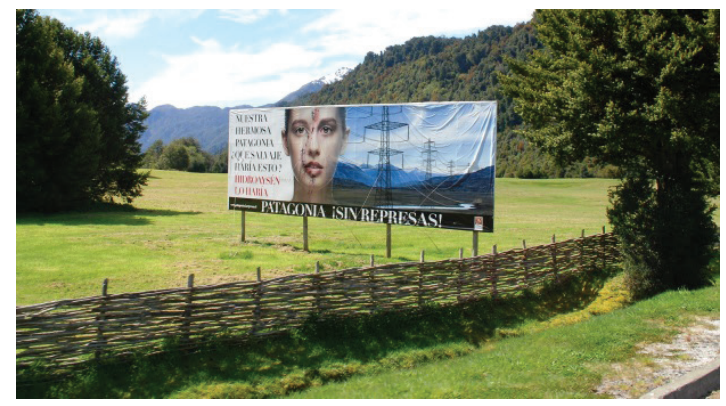

Fuente: fotografía de los autores. 


\section{Las marcas en el territorio}

La dificultosa accesibilidad ha jugado un papel importante en las producciones discursivas sobre el territorio en la entrada del siglo XXI. La accesibilidad marca las potencialidades de interacción, por lo que está asociada a la frecuencia de las mismas y la velocidad que adquiere el territorio. Localmente, da cuenta de las posibilidades que cada comunidad tiene para conectar la relación entre origen y destino, conforme a los medios de transportes susceptibles de ser utilizados. Las decisiones tomadas remotamente han afectado a la Patagonia en aspectos que resultan un poco inverosímiles y que han afectado por décadas el ordenamiento territorial: luego de diversos recorridos, entrevistas con lugareños y revisión cartográfica, no es difícil evidenciar que el área de influencia de la Carretera Austral tiene rasgos dramáticamente comunes como el bajo poblamiento, las dificultades de acceso y el aislamiento, por ejemplo. Rasgos que en la gran mayoría de los extensos más de $1.200 \mathrm{~km}$ de la vía se hacen extremos.

Así, no resulta claro por qué la provincia de Palena quedó en la región de Los Lagos, con Puerto Montt, Puerto Varas, Osorno, que son ciudades en el área de influencia de la Ruta 5 , con vías férreas y aeropuertos. Como tampoco puede entenderse el que localidades como Puerto Raúl Marín Balmaceda, La Junta y Puyuhuapi quedaran dentro del territorio comunal con capital en Puerto Cisnes (una a 7 horas, y las otras a 4 horas y 3 horas de viaje, que incluye cruzar uno de los tramos más difíciles de la Austral en el Parque Nacional Queulat). Como el que la dependencia municipal de Puerto Beltrand y Puerto Guadal sea la Chile Chico, con más de 100 km de ripio; situación similar de Puerto Tranquilo con la municipalidad de Puerto Ingeniero Río lbáñez (unos 160 kms).

Recién, a casi cuatro décadas de la fundación y delimitación de la mayoría de los territorios comunales realizada por la dictadura militar, se presentó y aprobó en el Senado de la República el Proyecto de Acuerdo (Walker, 2017) que propone un reordenamiento más adecuado, pero deja fuera uno de los peores que detectamos, la Comuna de Lago Verde.

La capital comunal es la aldea de Lago Verde, se encuentra a unas 2 horas de viaje desde la carretera Austral, por un camino ripiado de 72 kms, que sigue la cuenca del río Figueroa, pero más de la mitad de su reducida población (con un total de 852 habitantes, INE 2018) se encuentra en dos caseríos que están separados por numerosos cordones montañosos (incluyendo el Parque Nacional Queulat): la Villa Amengual a 202 kms y más de 5 horas de viaje, y La Tapera, a $256 \mathrm{kms}$, con 8 horas 46 minutos referenciales. Como la distancia en línea recta entre la capital comunal y éste último caserío - en el mapa - es de apenas $47 \mathrm{~km}$, no sería difícil creer que las fronteras de la comuna fueron trazadas a fines de los años 70, por algún funcionario uniformado mirando un mapa en alguna oficina en Santiago, en los años en que el Cuerpo Militar del Trabajo construía el Camino Longitudinal.

Para viajar de la Municipalidad de Lago Verde a cualquiera del resto de las localidades habitadas de la comuna, se tiene que recorrer casi 140 $\mathrm{km}$ por territorio de la comuna de Cisnes. Una vecino declara: "para ir a esos otros pueblos de la comuna hay que pernoctar allá [Villa Amengual, Tapera o la Estancia]: no sólo están muy lejos, sino que además para llegar hay que ir a dar una vuelta por la comuna de Cisnes. No 
sé en qué estaban pensando cuando hicieron así a Lago Verde".

Evidentemente que estos rasgos afectan negativamente la gestión del escaso poder autónomo de los municipios, pero también de las comunidades locales.

Sin postular a un determinismo geográfico, las dificultades de penetración en su geografía física, es lo que ha puesto a este territorio a resguardo del extractivismo con chimenea, convirtiéndolo en un lugar extenso y deseable. Asimismo, ha fijado límites a la velocidad del capitalismo y a la figura del progreso, como aspecto central asociado al deterioro ambiental, la extinción de especies y el cambio climático. De este modo, en las tierras interiores, no solo tenemos una insularidad que en términos humanos ha aprendido a resolver problemas sin la presencia territorializada del Estado, y que lo ve lejano; sino también que esa población rural es preexistente a los descubrimientos recientes de empresas mineras, acuícolas, energéticas y los discursos y filosofías ambientalistas y conservacionistas.

Fotografía 2: Posta rural El Malito.

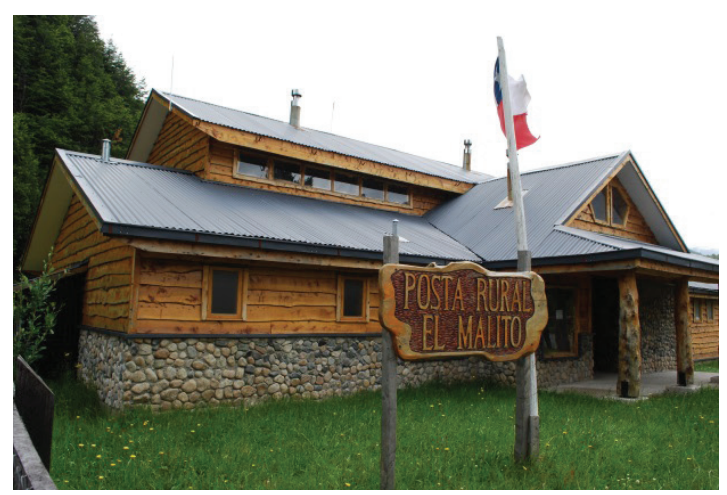

Fuente: fotografía de los autores.
La forma ocupada para colonizar las tierras australes fue concesionando grandes extensiones para desarrollar la ganadería, especialmente la ovejería, con el fin de marcar a través de privados presencia estatal en un país rentista y de arcas fiscales exiguas. Esto no implicó la fundación de ciudades o poblados con importante infraestructura y servicios para albergar a familias, sino solo muy tardíamente en la Patagonia-Aysén, hacia 1929, con lo que hoy sería la ciudad de Coyhaique. No se generó una red de caminos suficientes y eficientes para la producción ganadera, infraestructura portuaria significativa, ni se pudo obtener independencia alimentaria. El territorio se constituyó de la mano de la asignación de tierras para ganadería a compañías que las administraron a distancia (desde Valparaíso y Santiago) y tierras excedentarias ocupadas de manera ilegal o en disputa a las concesionadas, o en lugares alejados, con fines de sobrevivencia para poblaciones provenientes del otro lado de la baja cordillera de Los Andes, cuando Chile y Argentina trataban de fijar hitos fronterizos.

Con ello, tenemos un Estado territorializado de presencia tardía, de agenciamiento lento en su institucionalidad y con pocas convicciones sobre su valor. $\mathrm{Y}$, consecuencia de ello, un territorio fragmentado en pequeños poblados que en su mayoría no superan en la actualidad las 2.000 personas (i.e. La Junta, Puyuhuapi, Puerto Cisnes, Villa Amengual, Villa Mañihuales, Villa Cerro Castillo, Balmaceda, Villa Ortega, Puerto Ibáñez, Villa O'higgins), y población dispersa en caseríos muy modestos y alejados de todo beneficio social, lo que los vuelve muy vulnerables desde la perspectiva de la satisfacción de sus distintas necesidades. Esta condición espacial, demográfica y territorial, en la que solo existen dos ciudades (Coyhaique 
de una población cercana a los 60.000 habitantes y Aysén de menos de 30.000), primero, transforman a la Patagonia Aysén estadísticamente en un "desierto demográfico" (menos de 0.9 habitantes por $\mathrm{km}^{2}$ ); segundo, desde la producción de alimentos en un "desierto alimentario", por la dependencia del exterior al no desarrollar una producción estratégica; y, tercero, en la identificación de la región con paisaje verde y superlativo, más que por la sociedad y la cultura.

Entonces, el descubrimiento reciente de la riqueza que esconde este tercio del territorio chileno, como el agua, la madera, los minerales, la energía y el paisaje, en medio de una geografía en parte abrupta, telúrica, prístina, ignota y superlativa escénicamente, de "esas que ya no existen", es lo que hace que estas tierras de frontera, por conquistar, se vuelvan un "Nuevo Dorado" o una "posfrontera" en términos de Larsen (2015), aunque con acento en su paisaje y ecosistemas. La diferencia estriba en lo siguiente: "Mientras las fronteras representaban un territorio inexplorado fuera de la vista y control, la posfrontera está, en términos narrativos, visualizada, inventariada y administrada. Mientras las misiones fronterizas hacían mapas de las vías e inventarios de los conversos e infieles, los mapas de la posfrontera registran comunidades de plantas, áreas protegidas y territorios indígenas. Mientras en la en la frontera el desarrollo ponía un orden "civilizado" en la naturaleza y la tierra salvaje, la posfrontera, sobre el papel, impone el orden socioecológico de la civilización" (op.cit. 31).

Con ello, enfrentamos lo que señala Milton Santos: "Con la globalización, [-agregaremos el adjetivo de neoliberal-], todo o cualquier pedazo de la superficie de la Tierra se vuelve funcional a necesidades, usos y apetitos de Estados y empresas en esta fase de la historia" (Santos 2013:81), por lo que no resulta extraño el título de un reportaje de la revista chilena Capital (2014): "Patagonia Hot". En este, se alude a los magnates (o grupos económicos) que le han visitado con fines diversos, los que han conjugado para sus decisiones de compra o interés la relación entre precios y extensión en lugares donde no se ha puesto un pie aún, así como la privacidad que permite "escapar de la civilización", la seguridad y anonimato que ofrecería ${ }^{11}$. De ahí, entonces, que el "ámbito ambiental" contemporanizado de la Patagonia deba ser entendido como "el espacio de interacción social donde se decide sobre la vocación de los espacios naturales y sus componentes, sobre los derechos de acceso a los recursos naturales y sobre nuestras intervenciones en el entorno [y que sea], como en casi toda interacción humana, un espacio de tensión y contienda" (Durand et al. 2012:21).

Así, por una parte, la disputa presente es entre los "fines territoriales" o las "vocaciones territoriales" que le son atribuidos por los diversos actores que construyen esta geografía, y que definen la posición de cada uno en la sociedad. Por otra parte, si esta atribución y derechos también le corresponderían por igual a quiénes ahí viven (por décadas ocupando tierras excedentarias), a la región como entidad política, al Estado nacional, a los particulares que han adquirido tierras y derechos dentro del régimen neoliberal, o al mundo como expresión de consciencia de la crisis ambiental que atraviesa el planeta. En este sentido, proteger

Se trata de un lugar donde no hay enfermedades, animales peligrosos ni violencia, lo que otorga un plus frente a otros lugares escénicamente imponentes. 
de una amenaza o recuperar lo dañado como fue la ambición de Tompkins y sus fundaciones- es un dispositivo político que pone límites, incorporado a los sistemas de acciones y objetos subyacentes o potenciales, esencialmente excluyente de algunas prácticas para quienes viven en el territorio para alcanzar la reproducción cotidiana y generacional. Es decir, como actor con derechos, Tompkins se convierte en un negociador frente al Estado, los inversionistas, las empresas y los campesinos.

De modo sucinto, existe una disputa por elegir un "nuevo destino" para este territorio por distintos imaginarios, porque el espacio está lleno de poder para la producción de nuevas formas espaciales, ya que se trata de un asunto relacional entre personas, cosas y lugares que dan estructura a la "geografía del poder" (Massey 2005). Cuestión que, supone problemas de gobernanza para organizar, participar y negociar en y sobre el espacio, entendido como la propiedad y la disposición de los objetos e infraestructuras que crean conjuntos para articular a las poblaciones, sus actividades y los recursos para su reproducción. Entonces, algunos actores con distinto peso estratégico y poder de negociación (el Estado y sus funcionarios y normativa, ambientalistas, empresarios, campesinos, especuladores, inversionistas, políticos), proyectualmente a través de sus imaginarios entran en la arena del conflicto mayor, ya que la especificidad de cada uno de los lugares es producto de cuestiones más amplias, siendo justo aquello lo que está en disputa (Massey 2005). Hay grupos que están fuera del espacio geográfico de Aysén y la Provincia de Palena que hegemonizan la capacidad de tomar decisiones sobre ella; en la geometría del poder, la Patagonia como lugar de enunciación tiene sólo opciones marginales.
Este conflicto, planteado ahora como "socioambiental", refiere a "lenguajes de la valoración" -hábitat, paisaje y económico(Martínez Alier 2014:49-51) y "escenarios y procesos sociales con una marcada polarización de intereses en relación con el manejo, acceso y explotación de los recursos naturales, lo que da lugar a posturas radicales y que en ocasiones desbordan los ámbitos locales y estatales" (Guzmán y Madrigal 2012:99), ya que se encuentra asociado también a la búsqueda de oportunidades para la reproducción del capital, que desde los años sesenta está mostrando problemas en el proceso de acumulación (Harvey 2007). De ahí que, la forma específica que adquiere el territorio pensado en clave verde, pueda ser una variación del neoliberalismo, ubicándose en la esfera del mercado, o que pueda ser también desafiante del mismo.

En estos territorios en disputa, analíticamente estamos frente a un problema clásico del poder y control de los recursos, y otro, de discusión abierta sobre los modos de vida y el derecho a elegir cómo vivir dentro del territorio; ya que las tierras sometidas a protección por SENASPE o por iniciativas privadas, son una objetiva limitación para la población rural, ya que se trata de normativas y reglas concebidas autónomamente, y son opuestas a la memoria productiva subyacente (i.e. usar el bosque, el agua y las praderas como si fueran propias). Además, lo importante y nuevo, es que las disputas entendidas como significantes en tensión, también se manifiestan desde lugares extraterritoriales (fuera de la región y del país) y técnicos "contraexpertos"; que son "lugares políticos", como son los movimientos sociales que luchan por la tierra, el agua, contra la megaminería, la producción invasiva de energía y los agronegocios (Tobío 2012:154), y que 
arrastran una "identidad idealizada" frente al "suelo en que se introduce" (Massey 2005:56).

Fotografía 3: Plaza de Futaleufú.

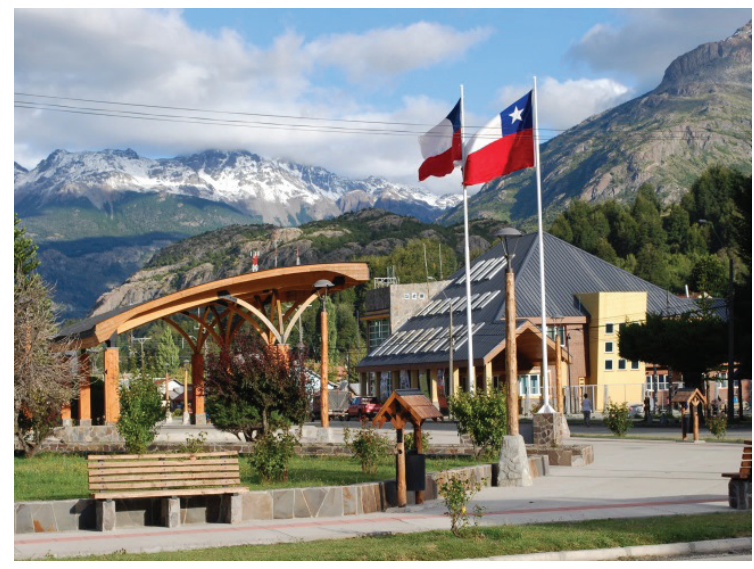

Fuente: fotografía de los autores.

Fotografía 4: poblado de Futaleufú

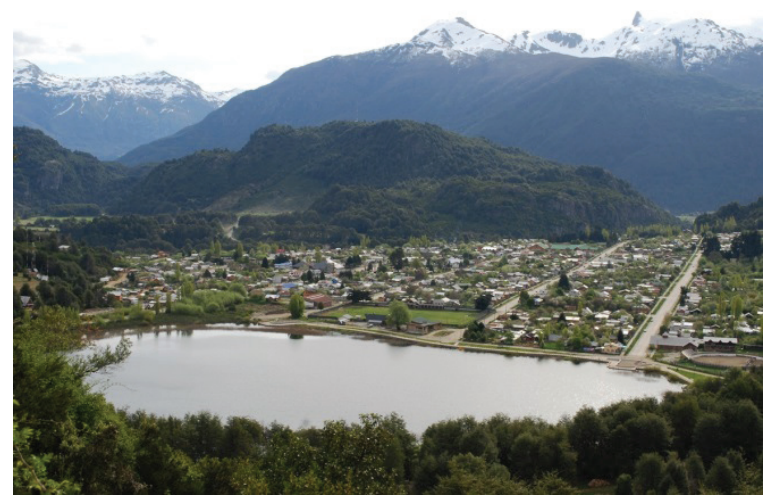

Fuente: fotografía de los autores.

\section{Nuevas configuraciones territoriales}

El territorio de la Patagonia está investido en la actualidad de un conjunto de significantes verdes, en el que se pueden tener experiencias originales (i.e. sobre el tiempo), los que operan como modos de aprehensión de la vida humana y de los ecosistemas. El territorio es una manifestación espacial de lo social; las diversas infraestructuras y las acciones humanas puestas sobre el espacio son las que permiten ir dando forma a un modo de ser comprimido para las poblaciones originarias y una nueva comprensión material y simbólica del mundo para otros, como expresión de las relaciones de poder puestas sobre él y que permiten su escritura. Entonces, desde una economía política antropológica en la que se juegan y combinan cuestiones estructurales y en parte la libertad de los sujetos (Roseberry 2014), debemos observar: ¿de qué modo se localiza la modernidad mundo? y ¿qué tipo de ocupantes participan?; si éstos son ¿activos o no activos?, ¿visibles o invisibles?, ¿particulares o institucionalizados? y ¿cómo dialogan con sus narrativas? Entonces, en términos territoriales, no se trata de descubrir la totalidad, sino de observar "el proceso totalizador" que está aconteciendo (op.cit.).

Las respuestas son cuestiones extremadamente importantes para caracterizar el territorio dentro de un régimen de acumulación flexible, que da paso a "lugares también flexibles" (Ortiz2005:55). Los usos conferidos al espacio-territorio pueden ser materiales y vinculados a la reproducción como en el caso de la población local que usa el bosque y las praderas para la ganadería; usar el río para un turismo de experiencias o para campeonatos mundiales de pesca con mosca, o estar en el extremo opuesto, sin uso 
conocido, o mantenidos como áreas protegidas y de conservación privada o estatal. Más aún, porque "los paisajes se desconfiguran" a través de los dispositivos regulatorios, induciendo la pérdida de centralidad de una actividad, de una condición o de la deslocalización de su requerimiento (op.cit. 50), lo que implica un cuestionamiento a los hábitos inscritos y arraigados en el territorio. Entonces, con las nuevas configuraciones territoriales propiciadas por las lógicas de protección y recuperación de ecosistemas (i.e. el turismo como actividad económica de nicho), se produce una cuestión jurídica, que obliga a prestar atención a la antigüedad de la permanencia de algunos ocupantes, y si ésta les entrega algún derecho especial que pueda ser reconocido.

Imaginarios de corte ambientalista, conservacionista, extractivista, recreativo, de refugio, geopolítico y productivo tradicional, convierten al territorio en un texto en construcción no sincrónico y armonioso, es decir, fomentan relaciones que producen geografías del poder específicas, en atención a procesos inducidos, acciones y objetos que les marcan para configurar una nueva ruralidad (ver Figura 1). El texto-territorio no se puede leer en única clave: primero, porque hay referencias culturales e imaginarios desterritorializados que provocan reterritorializaciones; segundo, porque es de incerteza para quienes lo vivencian cotidianamente (i.e. posibilidades de uso u ofertas de compras de sus predios), y con certezas mayormente controladas para quienes lo encuadran dentro del desencanto de la economía neoliberal (i.e. parques de conservación) o de quienes naturalizan la necesidad de invertir para desarrollar (i.e. la ganadería bovina para la producción de carne con sellos de certificación de origen).
Figura 1: diagrama funcional de agentes, intereses y recursos.

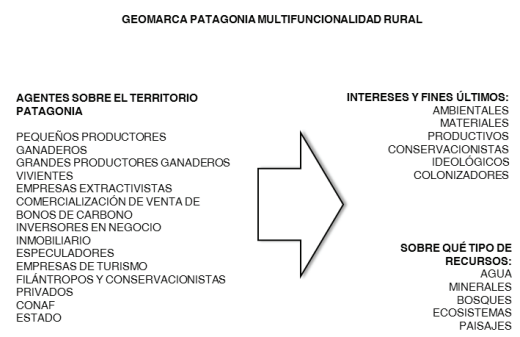

Fuente: elaborado por los autores.

Los movimientos de oposición a cualquier intervención de corte extractivista, especialmente los conservacionistas como el auspiciado por Douglas Tompkins y sus fundaciones, tienen al frente la depredación como rasgo dominante y una interpelación hacia el Estado y las empresas ${ }^{12}$. Lejos están de considerar que se trata de un problema técnico -como diría Latouche (2014:31) - y que podría corregirse; sino que corresponde a una propiedad de la desmesura humana o la "megamáquina" capitalista, que ha generado la crisis del cambio climático y la extinción de especies. De modo que, la afirmación "la Patagonia No", que tiene a su espalda la erosión y desforestación, y como gran metáfora lo regional y nacional y también mundial, no es solo una interpelación a la matriz de lo ilimitado, del desarrollo que supera la ecúmene y los límites de la biosfera (op.cit. 29), sino una invitación urgente a reterritorializar la vida (op. cit. 31). Expresa un progresivo reconocimiento y concienciación de la relación mutua entre el hombre y la biosfera; revela que el bienvivir está

\footnotetext{
Ver: La tragedia del bosque chileno, 1998.
} 
indisolublemente ligado a las posibilidades de existencia de los otros seres, libres y sanos, y que dependemos de ellos.

El ambientalismo más militante conocido en la Patagonia, el de la "ecología profunda"13, que da continuidad al conocimiento científico y filosófico (ver Naess 1990), y representado en la figura del fallecido Douglas Tompkins, se sostiene en la convicción de una "realidad relacional" y en un particular concepto de belleza, que en su médula es restaurativo. Se apoya en la belleza como principio básico, para que la sostenibilidad signifique algo; la belleza pensada como equilibrio es lo que da realce a los vínculos y a la vida misma. La belleza está en las plantas, en el bosque, las praderas y las masas de agua, y esencialmente en su codependencia. $Y$ en esa medida, la propuesta de generación de grandes corredores para el fortalecimiento de la biodiversidad para llegar al disclimax, no requiere de fauna exógena (caballos, ovejas y vacunos) ni de la participación del hombre como homo economicus que explota las praderas o el bosque (ver Rodríguez et al. 2016). Más bien, este último es considerado un depredador; de ahí que se necesite de una "próxima economía", una economía basada en la frugalidad, en el ahorro, el cuidado y la conservación ${ }^{14}$.

13 La ecología profunda corresponde a un minucioso cuestionamiento acerca de la validez de lo establecido y de lo vigente, es decir, al sistema social y económico basado en el control de unos por sobre otros. Se plantea filosóficamente el valor del mundo no humano y reconoce el idéntico derecho a vivir y a prosperar de todas las formas de vida sin excepción, postulando a un igualitarismo biosférico. A partir de este principio de interdependencia entre los seres, reconoce que existe una guía para organizar las relaciones sociales.

14 Véase una explicación más amplia en el siguiente link: http:// www.tompkinsconservation.org/sp/vision_and_values. htm\#prettyPhoto/0/
Fotografía 5: Familia de guanacos en la ex Estancia Chacabuco, propiedad de Douglas Tompkins.

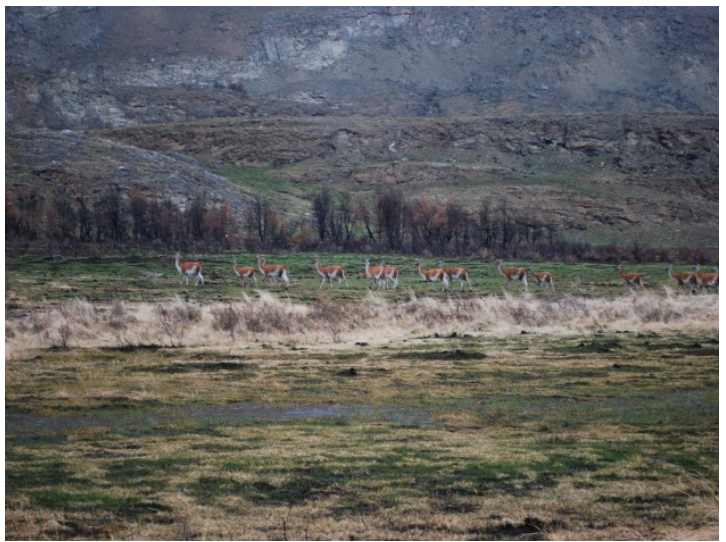

Fuente: fotografía de los autores.

En esta perspectiva, la tensión que provoca frente a cualquier interés extractivista o de nuevos desarrollos de la ganadería, es máxima en términos de contradicción. De ahí que nos parezca prudente que al leer el territorio en su proceso de territorialización y reterritorialización, se deben registrar al menos cinco cuestiones en una perspectiva de economía política antropológica:

1. Valorizar las relaciones y los procesos: resaltando la territorialización como proceso en marcha, más que aquello que descansa en la estabilidad y que conduce a otorgar cierto esencialismo construido en el pasado pionero y colonizador ganadero;

2. Asumir que lo local no tiene un contorno preciso y restringido en el que acontece la cotidianeidad, y que es menester observar las inflexiones entre la idealización de la identidad y el espacio a la cual se le asocia; 
3. Reconocer que un territorio tiene siempre distintas temporalidades y velocidades, lo que genera mayor fluidez o estabilidad, o mayor estabilidad que fluidez, lo que expresa también mayor o menor propensión al cambio;

4. Distinguir si los territorios bajo análisis, desde la perspectiva del poder expresado en imaginarios y compras de tierra, tienen una mayor carga funcional (material) o una predominancia de aspectos simbólicos ${ }^{15} ; \mathrm{y}$,

5. Si es posible pensar la historia local al margen de la historia global o universal, o pensar lo micro sin lo macro.

Exponemos lo anterior, aunque se trata de una cuestión que es objeto de otro escrito, porque las posibilidades de mantener cierta autonomía dentro delasestructurasterritorialesson disímiles entre los actores, y ello está en relación con la posesión de los recursos comunicacionales, técnicos, financieros y los derechos adquiridos. Hay legitimidades desiguales puestas en el territorio de la Patagonia Norte chilena, las que determinan la espacialidad, lo que induce a que las unidades de agricultura familiar campesina (AFC) dejen de ser unidades autónomas, que puedan controlar su propio tiempo y el alcance de su actividad productiva. Sabemos que lo importante en la agricultura familiar no es solo la característica de la unidad productiva y la mayor o menor orientación que tiene en relación al autoconsumo o al mercado. Son extremadamente importantes para hacer frente al pensamiento único de la agricultura industrial, especialmente cuando la hoja de ruta de los países señala o insinúa que deben convertirse en potencias alimentarias; además, porque

15 El dominio territorial concreto puede tener una ambivalencia entre lo material y lo simbólico, incluyendo o excluyendo personas a través de restricciones o por las posibilidades de usufructo. la agricultura familiar campesina sostiene dos elementos substantivos: 1) la soberanía, específicamente alimentaria; $y, 2$ ) el control sobre el territorio y su biodiversidad.

Entonces, sonestaslasunidadesqueseenfrentan a los cercos privados que impiden el acceso al agua o al bosque, por los que transitaban por décadas; a portones y cuidadores que impiden el paso marcando la propiedad privada o a los corredores de biodiversidad; o, a las normativas de la Corporación Nacional Forestal (CONAF), que regulan el acceso al bosque y lugares únicos o fuertemente sometidos a amenazas.

Fotografía 6: puente - sendero construido con árboles muertos en el Parque Pumalín.

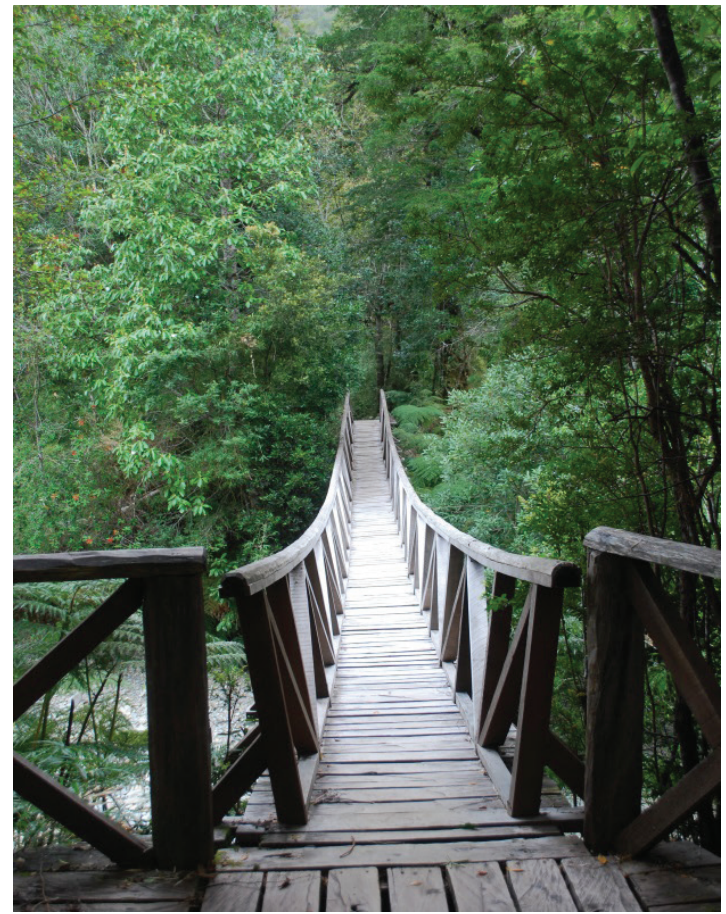

Fuente: fotografía de los autores. 
En este sentido, reconocemos tres condiciones estructurantes que impiden la reproducción social y biológica de la AFC. Primero, se debilita la soberanía a través de la pérdida de la titularidad del derecho a la tierra y se imposibilita que las bioregiones puedan escribir su historia territorial de manera autónoma. Segundo, como ideal de democracia, la idea de soberanía corresponde a la posibilidad que una comunidad trace su propio destino en base a su voluntad, lo que está cuestionado fehacientemente. Tercero, que pueda controlar su territorio, sus recursos, su arraigo, identidad y derechos para procurarse el autosustento, porque finalmente son los elementos que dan sentido a la propia realidad y el fundamento necesario para impulsar el propio desarrollo. En el largo plazo, no se vive de la renta, o del extractivismo; se vive del trabajo de las personas.

La soberanía siempre lo es sobre la conservación de los territorios y sobre los distintos patrimonios ahí existentes. Básicamente, para sostener la autonomía, es decir, hacia dónde ir y cómo hacerlo, entran en juego las capacidades e historias humanas que le dan vida y los recursos genéticos disponibles para que las comunidades puedan controlar el diseño de sus propias vidas, procurando simultáneamente la reorientación de los recursos del Estado, evitando la monopolización o concentración en algunas regiones, o la concentración de los recursos en pocas manos.

Obsérvese por ejemplo, una sola entrada en el buscador Google, referida a la venta de tierras en la Patagonia Norte, por parte de la compañía Mirr Ranch Group: 1) Río Palena, Palena, 119 acres por USS 690.000; Jeinimeni, Chile Chico: 3.144 acres por USS 2.381.000; Lago Espolón, Futaleufú: 600 acres por USS 1.908.648; Fundo
Los Leones, Aysén: 1.700 acres por USS 2.950.000; Tortel, Caleta Tortel: 3.548 acres por USS $1.495 .000^{16}$

Dos precisiones son importantes de resaltar frente a lo señalado: 1) no se compra terreno, se compran ecosistemas; 2) a espacio privado, se establecen reglas privadas. En esta categoría está El parque Pumalín, propiedad del ecologista Douglas Tompkins, que está ubicado en la Provincia de Palena, $X$ región, y posee una extensión de 230.000 hectáreas. Es un parque de conservación privado que va desde la cordillera al Océano Pacífico, cuya finalidad es generar protección a una importante reserva ecosistémica, en el que se incluyen grown forest, conciliando valores asociados a la conservación, el buen vivir y la vida saludable, junto con un activismo en favor de la defensa del derecho a la existencia de todos los seres vivos. La Estancia Chacabuco, del mismo propietario, está ubicada en Cochrane, XI región, fue un enclave ovejero de 70.000 hectáreas. Inicialmente propiedad de Lucas Bridges (1908), luego parcelada en el período de la reforma agraria (1964), y posteriormente subastada por el belga Francoise Smet -como efecto de la contra reforma agraria (1980)-, hasta que fue adquirida por la Fundación Conservación Patagónica, que dirigía el mismo Tompkins, que logró anexar otras 10.000 hectáreas. Se trata de un proyecto en el que estas tierras se unen a las de la Reserva Jenimeni (norte) y las de la reserva Tamango (sur), que dan forma al gran Parque Nacional Patagonia de 230.000 hectáreas. El objetivo es la creación de un gran corredor de biodiversidad, y proteger y restaurar las tierras degradadas por efecto de la ganadería durante un siglo.

\footnotetext{
Véase: www.mirrrancgroup.com/ranches-for-sale/patagonia
} 
De ello se desprende un modelo de conservación de especies de flora y fauna, y de expulsión de especies introducidas, de reforestación nativa y de contención de actividades invasivas, distintas a las del extractivismo como es la forestación de especies de crecimiento rápido (Rodríguez et al. 2016). De este modo, para ser eficiente la filosofía restaurativa de Tompkins, se requiere de la formación de grandes corredores biológicos; es decir, conectar predios y aumentar el enlace ecológico para favorecer la recuperación de la cobertura vegetal y detener la extinción de especies.

De este modo, la concepción biologicista como dispositivo se impone por sobre otras consideraciones sociales y económicas. La complejidad de esta propuesta no está conceptualmente en la figura misma del corredor, los distintos hábitats y la extensión del mismo, sino en la heterogeneidad espacial; no se puede escapar a la premisa de que los territorios por definición son socioecológicos. La tierra tiene presencia humana y la propiedad tiene límites; muchas de ellas son ocupadas por campesinos y ganaderos pobres que no pueden compatibilizar su sobrevivencia con objetivos loables y filantrópicos, o con principios filosóficos como la restauración y la conservación, porque son simultáneamente víctimas y victimarios por limitaciones históricas que hemos detallado. Por ello, cuando existe conflicto con algunas claves de "lo verde", lo que se pone al frente es la gran asimetría en la distribución de la tierra en la Patagonia y en el poder. Los antiguos colonos enfrentados a tierras degradadas requieren de grandes extensiones para la reproducción de su ganado y su unidad familiar, y en el día a día necesitan aumentar la renta, el bienestar, reducir la pobreza y disminuir la vulnerabilidad.
Cuando los predios de estos colonos quedan próximos a los parques de conservación del Estado o privados, su vida se fragiliza y es muy difícil que acontezca el co-manejo. Sienten que se enfrentan a ordenanzas y reglas que impiden hacer uso (extensivo) del bosque y las praderas para la reproducción del ganado, ya que un bovino requiere de 4,5 o 6 hectáreas para su alimentación, por lo que 500 o 600 hectáreas para sostener una masa ganadera no implican gran capital ni ganancias. Pero, además, producto de estas tierras sujetas a otros objetivos (i.e. conservación o servicios ambientales a través de la venta de bonos de $\mathrm{CO}^{2}$ ), se quejan por el aumento de pumas que amenazan su ganado y merman sus rebaños, ya que la recuperación de la fauna local depredadora es un objetivo para los conservacionistas.

Entonces, hoy lo subyacente etnográficamente a la ruralidad tradicional, corresponde a una lógica espacial que caracteriza una cierta movilidad que funde tiempo y espacio, ya que define una condición global sobre lo local y un repertorio acotado de posibilidades de desplazamientos para las AFC. Ello implica la modificación de posibilidades de adquisición de bienes y servicios que contribuyen a la canalización de la renta, lo que opera como red de relaciones sociales que perfilan los sistemas de referencias y los contenidos que definen la cultura e identidad de la población local correspondiente a pequeños productores de ganado.

En este sentido, por una parte, es difícil pensar al margen de cierta hibridez fundante en los procesos de territorialización en la Patagonia contemporánea; por otra, sin pensar en los procesos de gobernanza, y a través de ellos de la fragilización de algunos 
tipos de unidades productivas por presencia de otras espacialidades que operan vertical y horizontalmente. En lo fundamental, tomando un término usado en lingüística, acontece una diglosia. Es decir, una especialización (sistémica e ideológica) con usos diversos del espacio, por lo que los lugares son espacios de la diferencialidad, como si fueran lugares donde se expresan varias comunidades de hablantes (visiones de mundo) con sus jerarquías.

\section{La gobernanza}

La gobernanza corresponde a un proceso de "organización, participación y acuerdos entre instituciones y actores (agentes), en diversas escalas (local, regional, nacional e internacional) y diversos ámbitos del mundo económico social (certificaciones, cadenas globales de producción agrícola o manufacturera o pagos por servicios ambientales), que determina las formas y modalidades que definen un territorio en particular" (Rosales y Brenner 2015:9).

En este sentido, el territorio de la Patagonia Norte en la región de Aysén, constituye no solo la decantación de la gobernanza, sino que la propia gobernanza es un elemento fundante de la espacialidad, como expresión material y simbólica de las relaciones que la configuran. De suyo, la gobernanza es siempre materialización de la espacialidad; no hay territorialidad sin una forma de gobernanza que fije y regule las formas posibles de la acción y el movimiento. De este modo, al introducir la idea de la gobernanza estamos frente a las escalas y manifestaciones propias del poder y la economía; también, y en lo fundamental, la relación específica entre lo global-local, en la medida que lo sistémico global corresponde a un ámbito de construcción de lo territorial local que se expresa en el mercado de tierras, en la venta de servicios ambientales y en las filosofías puestas sobre el espacio y paisaje.

Si la relación global-local y local-global (por presencia u omisión) es una cuestión fundante de esta territorialización, lo es porque la gobernanza define un conjunto de cuestiones esenciales y que afectan de manera desigual a los sujetos singulares 0 institucionales. Esto es: inversiones, redes productivas y de comercialización, especulación y transformación de ejes históricos de las maneras de alcanzar la reproducción cotidiana y generacional. Tratándose del ámbito de lo privado, los objetivos de la gobernanza (relación de poder y económicas) están en la adecuación flexible de lo local a cadenas internacionales, las que pueden ir desde el turismo al extractivismo, pasando por la conservación, dentro de las contradicciones propias del capitalismo (i.e. plusvalía verde o extractivista).

En este sentido, el campo ecopolítico lo es en relación a aspectos globales y locales comprometidos. El emplazamiento mismo de agentes y actores, humanos y no humanos, habla de la construcción del medio ambiente (Di Giminiani et al. 2016) como dimensión territorial; los discursos y las acciones desde la perspectiva biológica y la naturaleza son una práctica eminentemente política, pero también bidireccional (Di Giminiani et al. 2016; Martínez Alier 2014; Escobar 2001). De este modo, la gobernanza nos plantea necesariamente una cuestión adyacente a la configuración territorial: la autonomía/soberanía de las poblaciones y sus territorios, considerando un deterioro de lo que Di Giminiani y Fonck (2015) llaman "relaciones agenciales", como marcadores de domesticación de un recurso, que están más 
allá de una consideración abstracta de una comunidad (i.e. bosque y actividades humanas). Con ella, pensamos obligatoriamente en la perspectiva de las decisiones y la trama de posibilidades de negociación económicas, financieras y jurídicas que definen en gran medida la dinámica de la ruralidad y de las comunidades. Así, sus efectos revelan una cantidad impresionante de microprocesos, los que a veces pueden ser definidos en el ámbito nacional y otros que exceden a ellos (i.e. venta de bonos de carbono; áreas definidas para investigación; potencial construcción de un enclave judío; identificación de lugares eutópicos para vivir; negocios de baja escala como lodges de pesca), y que van forjando y produciendo procesos de desnacionalización y socavamiento de las memorias productivas asociadas a recursos específicos.

Entonces, frente al mercado de tierras en la Patagonia, etnográficamente podemos prestar atención a lo estructural y los subjetivo para decodificar estos aconteceres en lo que significa el hogar, la movilidad, el abandono de terrenos productivos, las diásporas, las fuentes de ingreso, la caída en la demografía y el descenso en la productividad. Muchas de estas cuestiones son invisibles dentro de los grandes números. También, y así hay que decirlo, poco o nada podemos hacer para contener la transformación y la pérdida de memorias que involucran los procesos. Sin embargo, por una parte, son estas microhistorias que anudan tiempo espacio las que demuestran que lo que está en juego es la reorganización territorial de las regiones, el país y la fisonomía del mismo; $y$, por otra, la posición misma de los sujetos en cuanto a su reconocimiento y la probabilidad de sobrevivir como cultura del trabajo en un régimen de propiedad neoliberal y una Constitución que no reconoce ni protege derechos asociados a pertenecer y al permanecer en un territorio.

Es difícil no pensar que la organización social y económica no exprese procesos de negociación en un contexto extralocal, o más aún, de globalización. Por tanto, una cuestión básica desde lo local, identificados los recursos valorizados o los potenciales, es que la negociación en el ámbito de la gobernanza no tiene solo como interlocutor a la institucionalidad del Estado, sino a fuerzas económicas y políticas intersectoriales e interempresariales, las que ponen el conjunto de los recursos locales en normativas y cadenas de valor productivas y comercializadoras a nivel mundial (i.e. la construcción de centrales hidroeléctricas asociadas al proyecto HidroAysén; la compra de tierras y privatización de recursos con fines de conservación).

En este sentido, por ejemplo, un territorio ganadero como el de la Patagonia, donde la memoria productiva de las unidades familiares campesinas demuestra que su productividad está destinada al autoconsumo y al intercambio simple, el territorio puede alcanzar su máxima valorización en una dimensión ambiental conservacionista. Es decir, el paisaje único, agreste, de difícil acceso, telúrico como goce escénico y como provocación y activación de los sentidos, puede ser incorporado a un circuito internacional de turismo exclusivo, y de las tierras deseables de adquirir a través de cadenas inmobiliarias transnacionales, con fines estéticos, conservacionistas o por el simple deseo de querer adquirirlas. Y, conforme a este cambio de "vocación" o reterritorialización, por una parte, el texto territorio se vuelve "deseablemente verde", está protegido porque 
lleva la marca regional "Reserva de Vida"17; invita a las buenas prácticas, a la reconciliación con la naturaleza, al reencuentro con sí mismo y situarse en las antípodas de lo urbano, el consumo y el capitalismo; por otra, relanza el territorio como geomarca (Rodríguez et al. 2014) a través del prefijo ECO, es decir, lo excede al revestirlo de un aura de paraíso planetario, de santuario, de casa que no se puede tocar, de fragilidad, ubicándolo en un circuito internacional (global). Diremos, un paraíso para consumidores exclusivos y verdes, de altos ingresos, de aventureros que pueden elegir cómo escribir cada día su biografía, controlando su propio tiempo de viaje, lo que permite el desarrollo de instalaciones y servicios de máxima sofisticación y confort en la periferia de Chile y del mundo.

Fotografía 7: vivienda de descanso, aislada, sin vecinos y de propietarios extra Patagonia.

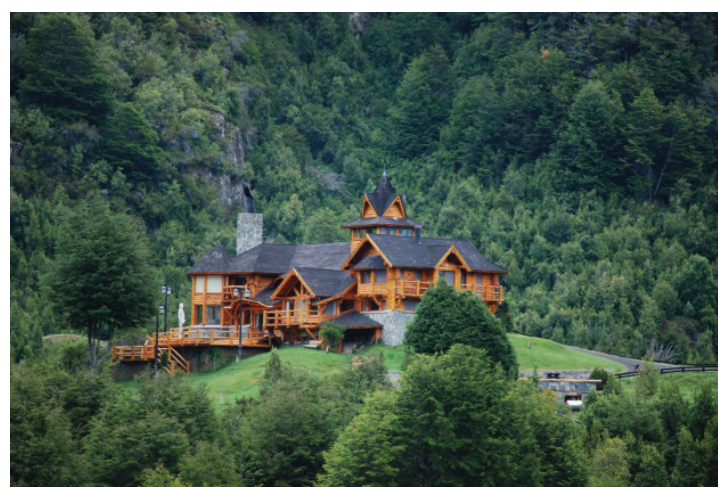

Fuente: fotografía de los autores.

"Aysén, reserva de vida", constituye en términos positivos el eslogan regional ampliamente difundido en la folletería, sitios de internet e instituciones. Éste, por una parte, resalta la belleza exuberante y favorece la protección de la gran cantidad de ecosistemas terrestres, lacustres y marinos existentes; y, por otra, es contrario los proyectos que quieran alterar, modificar, destruir la flora y fauna silvestre, acumular desechos, degradar la tierra o destruir la biodiversidad, o iniciativas que obstaculicen la reparación o protección de los ecosistemas.
Así, se imponen los eco-corretajes como un modelo anticipatorio de contención de otras formas de generación de rentas, en una tierra rica que puede ser depredada por el extractivismo. Se trata de un modelo refundacional de control del espacio y construcción de territorio, orientado hacia el negocio autofinanciado y de la conservación, en el que personas naturales compran una membresía y se incorporan a una comunidad que controla grandes extensiones de tierra, las que pasan a ser colectivas $^{18}$. El derecho adquirido, uno entre los que poseen el resto de los comuneros, otorga derechos individuales para una porción de terreno en el que se puede desarrollar un emprendimiento de baja intensidad como la construcción de la propia vivienda de descanso o un pequeño hotel; las actividades permitidas son no invasivas, no motorizadas y tiene como fin no alterar la vida de otros seres.

Por ejemplo, el modelo de negocios impulsado porlaempresaPatagoniaSur(www.patagoniasur. com $)^{19}$, tiene como trasfondo la compra de ecosistemas completos. La construcción de los inmuebles en sus predios, se desarrolla con materiales no contaminantes; se favorece ante todo aspectos ecoturísticos asociados al anonimato y la intimidad, la forestación con flora nativa y la venta de bonos de carbono. La comunidad tiene el control de unas 3.200 hectáreas distribuidas en varios predios, de las cuales solo unas 237 son susceptibles de ser ocupadas por los inversionistas, y espera que

18 Eso no es impedimento para que a futuro el negocio no tenga un giro hacia inversionistas institucionales, que sean poseedores de grandes extensiones, y que deseen otros fines.

19 En la portada de su página principal se indica lo siguiente: "Patagonia Sur es una empresa dedicada a la conservación que protege y desarrolla propiedades escénicamente extraordinarias y ecológicamente valiosas en la Patagonia Chilena". 
los comuneros puedan recuperar la inversión inicial a través de la venta de la captura de $\mathrm{CO}^{22}$.

Se trata que todo permanezca casi inalterado. Agreste, salvaje e ingenuo, y que se pueda apreciar desde un ecolodges o una carpa de tipo yurts ${ }^{21}$. Se trata de una privatización de recursos que tiene la fórmula de una exclusiva membresía como si se fuera parte de un excelso club de golf. Señala un reportaje del periódico El Mercurio (2012), que: "Un lujoso paquete ecoturístico es la principal apuesta para proteger un exclusivo patrimonio de bosques, hielos milenarios y animales como la ballena azul"22. Otro periódico, La Tercera (2012), indica que: "Una semana con todo incluido en una habitación de lujo cuesta US\$ 5.800 por adulto. Además, quienes quieren tener una relación permanente con la Patagonia, pueden acceder a un club de membresías, limitado a 100 familias (ya cuentan con 53), por US\$50.000, lo que da derecho a estadías con precios rebajados, reservas anticipadas $y$ beneficios en otros clubes alrededor del mundo ${ }^{23}$. La revista Capital, citando como fuente a "Patagonia Brokers", señala como indicador de su valorización lo siguiente: "Hoy es más

20 Los bonos se venden de forma directa a US\$ 15 y cada uno equivale a una tonelada de CO2 absorbido. En el año 2012, la empresa tenía un millón de árboles comprados. Entre algunos inversionistas institucionales se encuentra la Colgate University, la marca de relojes Audemars Piguet y la armaduría Land Rover.

21 Las carpas yurts son refugios circulares utilizados por los nómadas mongoles que viven en las estepas de Asia. Se han rescatado esencialmente por su versatilidad, la estética y las condiciones para la vida espiritual; son poco invasivos, fácilmente desmontables y funcionales para la experiencia de inmersión en la naturaleza. Algunos también les han llamado glamping, concepto turístico que une experiencia al aire libre y glamour.

22 éase: http://patagoniasur.com/imagestext/Revista_Domingo_ PatagoniaRentable_2012_English_translation.pdf

23 http://www.latercera.com/noticia/estadounidense-evaluaampliar-fondo-de-inversion-en-la-patagonia/ difícil encontrar un empresario que no tenga tierra aquí, que descifrar quiénes sí tienen"24

Lo "Hot" (revista Capital 2014), aplica como un nuevo dispositivo de control territorial y nos indica en cierta forma un proceso de "neocolonización" (Núñez et al. 2016) y refundacional en el que participan "millonarios verdes" (o con su lado verde) y "conservacionistas", como una forma de estar in u off; como si el mundo de los negocios no estuviera completo sin quedarse con una suerte de porción de paraíso patagónico. Se trata de la participación en un ingente mercado de tierras, donde familias de colonos como Aguilar, Gómez, Fierro, Cruces y López, transan sus tierras a diversas sociedades anónimas, cuyos propietarios son familias empresarias locales como Luksic, Solari, Puchi, Ibáñez, Matte, y otros personajes del mundo de la política (Núñez et al. 2016).

Si observamos la fórmula de los ecocorretajes o econegocios como la venta de bonos de carbono, es cierto que operan como contención del capitalismo extractivista y depredador a nivel local, pues se trata de mantener la máxima superficie de cada ecosistema y de crear áreas naturales protegidas que sean adecuadamente representativas de dichos ecosistemas. Pero, igual que en la fórmula de constitución de los parques privados, la exclusividad es excluyente de las actividades tradicionales ligadas al bosque y la ganadería, en un lugar donde hasta ahora no se desarrolla la agricultura.

Se entenderá entonces, que la cadena de valor del territorio cuenta con una logística que supera cualquier imaginación de un productor

Véase:http://www.capital.cl/negocios/2014/10/17/94083/ patagonia-hot 
que posee 50 animales y 500 hectáreas de terreno, que en la Patagonia es una tierra bastante insignificante cuando se trata de tierras agotadas por el sobrepastoreo y la erosión. Y, además, éste productor y su familia, sin darse cuenta se convierten o se puede convertir en miembro de una "cultura relictus", en vías de extinción, que icónicamente adorna el paisaje como postal costumbrista, pero abstraído de su base material con la que construyó su posición y su identidad. De este modo, muy claramente hay una transición discursiva entre el pionero que inició el sueño a comienzos del siglo XX, arrebatándole las tierras a los estancieros beneficiados por el Estado; el colono que se asentó (hasta la década de los 80's del siglo pasado); y la figura de la "reserva de vida" avalada por grupos ambientalistas y personajes icónicos (desde los 90's en adelante). Así, en la Patagonia hay redes efectivas de producción y comercialización del territorio, de negociación, reglas, usos, procedimientos y normas; de asignación de recursos y acceso a la información. La diferencia entre unos y otros, es que no todos tienen las mismas reglas, redes y objetivos; a la vez, lo local participa de un nuevo espacio: el de la diversidad discursiva. Y cuando esto ocurre, la Patagonia, en tanto lugar, se pluraliza y nos obliga a hablar de lugares en la Patagonia.

En este esquema, institucionalmente puede ser más importante una política de desarrollo del turismo de intereses especiales bajo el sello de lo típico o costumbrista, que la protección de las unidades familiares campesinas; puede ser más significativo generar facilidades para el turismo a través de incentivos tributarios que la asistencia técnica y crediticia para la pequeña producción ganadera; puede ser de interés superior afianzar la logística para asegurar alimentos provenientes de otras zonas distantes a cientos de kilómetros, que desarrollar la producción de alimentos certificados para generar autonomía regional; o, más importante el control privado de la tierra que cuestiones geopolíticas cuando se ha tenido hipótesis de guerra con Argentina.

\section{El debilitamiento de la pequeña producción ganadera}

Una de las cuestiones que caracteriza a la Patagonia chilena es el debilitamiento de la pequeña producción de ganadería ovina y bovina, lo que viene arrastrándose por décadas, lo que tiene sus antecedentes en la década del 40 del siglo pasado. Lo nuevo, como hemos venido indicando, es la aparición de otras modalidades de tenencia de la tierra y una redefinición de los espacios en función de otras modalidades agropecuarias, cuestiones asociadas a mercados inmobiliarios o de simple contemplación en las últimas tres décadas, apreciándose un fenómeno tensionado entre otras rentabilidades, filosofías y la aparición de un control en ausencia por parte de nuevos propietarios, ya que muchas de las tierras "solo están ahí". Portanto, la homogeneidad rural como cultura del trabajo da paso a la heterogeneidad rural, y ésta a una heterogeneidad espacial no productiva en el sentido agropecuario, lo que etnográficamente identifica nuevos actores en la construcción del espacio, generando localizaciones fragmentarias de los mismos y una reconfiguración singular de lo local y las redes de desplazamiento. En este sentido, una cuestión capital es la diferencia entre la vivencia y experiencia del nuevo espacio, y otra, las condiciones para la reproducción.

Expresado en otros términos, y en un juego no exhaustivo de combinatorias para la 
escritura territorial y la aprehensión del espacio en su proceso de desterritorialización y reterritorialización, se puede apreciar que hay una escala espacial asociada a distancia y una temporal asociada a medios para acceder al predio, lo que se combina con tipos de residencia, dimensiones prediales, fines y actividades desempeñadas en estos.

En la escala espacial, la movilidad puede ser local-local; local-centro de servicios (poblado mayor o ciudad); local-nacional y nacionallocal; local-transnacional y transnacional-local. En la escala temporal de desplazamiento se encuentran los medios de transporte que permiten las operaciones: avión, helicóptero, automóvil, bus, barcaza, o su combinatoria. Esto, además, implica la consideración de horas de viaje. El destino puede ser hacia una residencia principal o secundaria, aunque también están las caracterizadas por el ausentismo; también son elementos a considerar las dimensiones prediales y los fines a los que están destinados: productivos tradicionales, filosóficos (conservación), de contemplación, especulativos, para la venta de bonos de carbono o el turismo, lo que puede significar desde el punto de vista de la experiencia actividades para sí o para otros.

Entonces, las combinatorias implican claramente una nueva territorialidad de los mundos rurales australes debido al avance de las nuevas cadenas de valor sobre poblaciones, ríos, lagos, montes y bosques. El descubrimiento de la riqueza escondida y de las tierras erosionadas y subjetivadas por la estética, impone determinados modos de producción y de generación de rentas; obligan a una reterritorialización de poblaciones enteras, las que ven imposibilitada la continuidad de sus modos de vida. En efecto, de lo que se trata en el mejor de los casos, es de una "agricultura sin agricultores"; y en otros, de paisajes rurales sin trabajadores rurales. Sobre lo señalado, dos anotaciones: 1) el surgimiento de una nueva categoría social, la de los vivientes (Rodríguez y Saénz 2017); y, 2) la conformación de un desierto demográfico.

\section{Los vivientes}

Los "vivientes" son los descendientes de familias pioneras o colonas de la Patagonia Aysén y de la Patagonia Palena, que muchas veces en gran aislamiento desarrollaron una vida muy entrópica producto de un patrón de asentamiento disperso, y siempre trabajaron sus propios campos para alcanzar la reproducción cotidiana y generacional. Su arraigo ha estado marcado por la actividad productiva localizada, con baja movilidad espacial, el intercambio simple y por los escasos servicios territorializados del Estado (Rodríguez y Saénz 2017), lo que los ha inducido a ser muy autónomos y recurrir de redes en Argentina para hacer frente a necesidades propias de una vida vulnerable.

Debido a los cambios indicados más arriba en términos de los imaginarios puestos sobre el territorio-, especialmente expresados en el mercado de tierras y las limitaciones objetivas que generan los parques nacionales y áreas protegidas, y los de conservación privados en relación al acceso al agua, el bosque y las praderas, los colonos han visto mermadas sus estrategias de reproducción tradicionales. Producto de esta nueva precarización y condición inferiorizada ante la no existencia de una política de desarrollo rural, a través de la 
venta de sus tierras se han transformado de trabajadores autónomos a asalariados o por cuenta propia.

Mientras un campesino y un agricultor producían para vivir, el "viviente" mora el campo sin producir para sí. Ya no cuenta con título de dominio, pero vive en el campo y no lo quiere abandonar. Vive de una renta, y de la venta de su fuerza de trabajo. Es peón agrícola, vigilante, carpintero, fumigador, excursionista; acompaña a turistas en grupos de cabalgaduras, es alambrador, operador de balsas lacustres y botero para pescadores deportivos que remontan los ríos y lagos. Organiza su vida económica en función de actividades múltiples, reforzando la idea de una ruralidad pluriactiva o nueva ruralidad. Su mujer, y sus hijas, también contribuyen al ingreso familiar: son mucamas de hoteles y lodges; prestan servicios domésticos en casas de descanso. El valor de sus trabajos puede ser cancelado deslocalizadamente, desde cualquier ordenador telefónico y desde cualquier parte del mundo (op.cit), ya que existen propietarios ausentes que el viviente no conoce.

Las oportunidades detrabajo del vivientesiempre están ubicadas en lugares hipervisibilizados, es decir, dónde el turismo o la especulación ha puesto su bandera. Los lodges de Aysén, de alto estándar, se ubican esencialmente en el eje turístico Balmaceda - Puerto Chacabuco, enfocándose principalmente en la pesca recreativa, la que se vende en marzo y abril para la temporada siguiente ${ }^{25}$. Por tanto, sin

\footnotetext{
Se pueden encontrar tres modelos de negocio: 1) el administrado por empresas familiares locales; 2) los desarrollados por norteamericanos que residen en la Patagonia (Patagonia Bristers o Green Baker Lodge); y, el impulsado por organizaciones conversacionistas (Fundo Los Leones, en Balmaceda, o Yelcho en Puerto Cárdenas, de Patagonia Land Conservation).
}

saberlo, la pluriactividad se hace parte de la estacionalidad incorporándolo en un circuito laboral globalizado, de integración vertical de los territorios para la industria del ocio y como parte de la trama de la nueva gobernanza. Participa de un mundo que mueve millones, de clase mundial; $y$, en una red de venta de experiencias verdes, de bonos de carbono o de empresas filantrópicas y conservacionistas, que hacen negocios locales y globales, con procesos contaminantes en otras latitudes.

Esta modalidad de ocupación, por una parte, es expresión de las transformaciones territoriales en términos de propiedad y las limitaciones de acceso a recursos; $y$, por otra, propia de los procesos migratorios intrarregionales y del abandono de la población más joven de tareas productivas de base agropecuaria. Al no existir ninguna regulación sobre estos procesos de concentración de la propiedad, subvencionar la propia pequeña producción agrícola, ni protección y reconocimiento de derechos como al permanecer después de los procesos pioneros y de colonización, el resultado es el siguiente:

a) venta de las propiedades, negociando con los futuros dueños la posibilidad de mantenerse habitando como cuidadores o prestadores de servicios, para patrones ausentes o desconocidos;

b) una búsqueda de empleo informal (temporal) en las inversiones tipo lodges, casas de descanso, propiedades destinadas a conservación bajo la modalidad de parques privados

c) emplearse, tercerizadamente, en obras de carácter público como construcción de sedes vecinales, plazas en los villorrios, manteción de obras menores en colegios o postas rurales, entre otros. 
Señalado lo anterior, la narrativa posmaterialista de la conservación y de la constitución de una "reserva de vida" en la Patagonia, apoyada también por el mayor número de parques nacionales y áreas de conservación del Estado y privadas, restringen las posibilidades de sobrevivencia de los colonos y de la proyectación de la memoria de la cultura del trabajo. Entonces, estamos frente a un nuevo proceso de acumulación por desposesión en términos de Harvey (2004), aunque también -en apariencia- a la contradicción funcional entre un capitalismo "verde" y uno "extractivista". Entonces, la posibilidad de "permanecer" en el territorio bajo la inspiración de un sueño como pionero o colono, es bajo posibilidades restrictivas; que implica un componente emotivo y sacrificial de dejar la propia tierra como experiencia, ritmo, rutina, esperanza y capital familiar, trabajándola para otros y transformando la vida localizada en un "valor refugio" (op.cit). De este modo, la fisonomía territorial es la de un desierto demográfico, con predios de propietarios ausentes y que no son concebidos para el trabajo agrícola-ganadero.

Sin embargo, si miramos el territorio en una escala más amplia, lo que estamos enfrentando en un proceso de transformación del territorio que no tiene ninguna continuidad demográfica y productiva tradicional, ya que está llena de demarcaciones materiales y simbólicas, públicas y privadas, con presencias visibles e invisibles; con rubros nuevos como la industria del ocio, que introducen objetos, prácticas, modos, gustos y estéticas para la práctica del kayac, raffting, trekking, el mountain bike o fly fishing. Es decir, las restricciones en el plano productivo y las nuevas ofertas de trabajo, obligan a las ventas o a los procesos de transformación de fuerza de trabajo libre en asalariada.

\section{Conclusiones}

Lo que hemos planteado, demuestra que los problemas que enfrentamos tienen historicidad y espacialidad, y que la espacialidad actual refleja una nueva sociedad, con importantes aristas en la gobernanza. Implícitamente, hemos introducido dos elementos que recorren el texto: 1) la idea de justicia; y, 2) la consideración de los derechos humanos. La primera, porque es una forma de oponerse a la privatización de los bienes colectivos como la tierra, el bosque y el agua. Y, la segunda, porque asegura dos derechos: a la alimentación y a permanecer en el territorio. Nuestra Constitución nada señala sobre esto. Pero, tampoco hay una discusión sobre el acaparamiento y concentración de los recursos ecosistémicos, especialmente con propietarios ausentes.

En el plano metodológico y también teórico de la Antropología, hay una necesidad de corrección de la mirada etnográfica en el plano de lo local. Lo que está en juego, son las características de las construcciones y ensamblajes sociales de los nuevos procesos de gobernanza. Es claro que, estamos frente a nuevos lugares de enunciación del poder. La conservación se transforma en un dispositivo sociotécnico, excluyente de poblaciones tradicionales.

En el ejemplo que hemos desarrollado, enfrentamos un problema de espacialidad del capitalismo de nuestros días. Cómo se anexan los territorios contemporáneos, y cómo se producen movimientos socioterritoriales diversos, es una cuestión que revitaliza el análisis y no pueden ser separados. La disputa entre imaginarios y la posibilidad de la gobernanza es, desde el punto de vista teórico, un lugar de refundación de lo político. Hay lucha social, reconstrucción 
de lazos y participación, y nuevos presentes en disputa, independiente de qué opción se tenga. Los territorios tienen una extensión dilatada frente a límites aparentemente fijos.

En la construcción de los territorios se expresan los poderes más visibles y materiales de las instituciones formales, o el poder simbólico e imaginario representado por diferentes grupos culturales que definen y limitan la espacialidad a través de reglas propias. Eso significa exactamente parques de conservación privados; eso expresa también la definición de parques nacionales o áreas protegidas.
De ahí que, el territorio sea construido permanentemente en juegos -que operan como líneas de fuerza- entre lo material y lo inmaterial, entre lo bucólico y la depredación, entre lo funcional y lo simbólico. Y, por ello, podríamos afirmar que todo intento eficiente por aprehender los territorios contemporáneos de la Patagonia, debe superar todos los dualismos y códigos binarios tiempo-espacio, fijo-móvil, funcional-simbólico. La construcción actual de la territorialización patagónica demuestra los intereses institucionales, los de las corporaciones, de las unidades productivas, y la visión del pasado y las luchas del presente.

\section{Bibliografía}

Boisier, S.1998 Post-scriptum sobre el desarrollo regional: modelos reales y modelos mentales. Revista EURE - Revista de Estudios Urbano Regionales, 24 (72)

Defensores del bosque chileno. 1998. La tragedia del bosque chileno. Ocho Libros Editores: Santiago.

Di Giminiani, P. y Fonck, M. 2015. El paisaje como proceso de vida: experiencias de domesticación del bosque en el sur de Chile. Revista de Geografía Norte Grande, 61: 7-24.

Di Giminiani, P., Aedo A. y Loera J. 2016. Ecopolíticas globales: medio ambiente, bienestar y poder. Santiago: Editorial Huerders.

Durand, L., Figueroa, F. y Guzmán M. 2012. Introducción. Hacia una ecología política mexicana. pp. 21-31. En La Naturaleza en contexto. Hacia una ecología política mexicana. Leticia Durand, Fernanda Figueroa y Mauricio Guzmán, editores. UNAM- $\mathrm{CIICH}-$ CRIM-EI Colegio de San Luis: México.

Escobar, A. 2001. "Culture sits in places: Reflections on globalism and subaltern strategies of localization". Political Geography, Vol. 20, № 2, p.139-174.

Facchinetti, G, Jensen, S. y Zaffrani, T. 1997. Patagonia. Historia, discurso e imaginario social. Ediciones Universidad de la Frontera: Temuco.

Gobierno de Chile-ILPES CEPAL. 2009. Estrategia Regional de Desarrollo. Satiago.

Gobierno de Chile. 2018. Plan Especial de Desarrollo de Zonas Extremas Aysén. Santiago.

Gobierno de Chile. 2009. Plan Regional de Ordenamiento Territorial de Aysén. Santiago.

Guzmán, M. y Madrigal D. 2012. "Naturaleza y sociedad en San Luis de Potosí. Apuntes para una ecología política", pp. 95-
135. En La Naturaleza en contexto. Hacia una ecología política mexicana. Leticia Durand, Fernanda Figueroa y Mauricio Guzmán, editores. México: UNAM- CIICH-CRIM-EI Colegio de San Luis.

Haesbaert, R. 2013. Del mito de la desterritorialización a la multiterritorialidad. Cultura y representaciones sociales, 8(15), 9-42. Recuperado en 15 de febrero de 2018, de http://www. scielo.org. $\mathrm{mx} /$ scielo.php?script=sci_arttext\&pid=S2007$81102013000200001 \& \operatorname{lng}=$ es\&tlng=es.

Harvey, D. 2004. El Nuevo Imperialismo. Madrid: AKAL.

Harvey, D. 2007. Espacios del capital. Hacia una geografía crítica. Madrid: Akal.

Instituto Nacional de Estadísticas (INE) 2018 Censo 2017.

Ingold, T. 2000 The perception of the environment: essays on livelihood, dwelling and skill. London: Routledge, 2000.

Larsen, P. 2015. Derechos indígenas, gobernanza ambiental y recursos en la Amazonía Peruana. Hacia una antropología de la posfrontera. Lima: IEP.

Latouche, S. 2014. Límite. Buenos Aires: Adriana Hidalgo.

Martínez Alier, J. 2014. El ecologismo de los pobres. Conflictos ambientales y lenguajes de valoración. Santiago: Quimantú.

Martinic, M. 2014. De la Trapananda al Aysén. Santiago: Ediciones Fundación Río Baker.

Massey, D. 2005. For Space, London: Sage.

Naess, A. 1990. Ecology, Community and Lifestile: Outline of an Ecosophy. Cambridge: Cambridge Universe Press.

Núñez, A, Aliste, E. y Bello A. 2016. Patagonia-Aysén, Reserva de vida: el discurso de la naturaleza como nueva utopía capitalista (Chile, siglo XXI). En http://www.ub.edu/geocrit/xiv_nunezaliste. pdf 
Ortiz, R. 2005. Otro territorio. Ensayos sobre el mundo contemporáneo. Buenos Aires: Universidad Nacional de Quilmes Editorial.

Otero, L. 2006. La huella del fuego. Historia de los bosques nativos. Poblamiento y cambios en el paisaje del sur de Chile. Santiago: Pehuén.

Patterson, 2015. 3 Challenges facing the UN's Sustainable Development Goals. World Economic Forum. https://www.weforum. org/agenda/2015/08/3-challenges-facing-the-uns-sustainabledevelopment-goals/

Pierson, C. 2004 The Modern State. NY, Routledge.

Rodríguez, J. y Saénz, J. 2017. "De Colonos a "vivientes". Una nueva Categoría social en la Patagonia rural Chilena". Revista San Gregorio, №18, pp.20-33

Rodríguez, J., Reyes, S y Mandujano, F. 2016. "Reconfiguración espacial y modelos de apropiación y uso del territorio en la Patagonia chilena: migración por cambio de estilo de vida, parques de conservación y economía de la experiencia". En Revista de Geografía Norte Grande, Nº64, pp.187-206.

Rodríguez, J. Medina P. y Reyes S. 2014. "Territorio, paisaje y marketing global: imaginarios en la construcción de la Patagonia como marca". Magallania, Vol. 42, №2, pp.109-123.

Rosales, R. y Brenner L. 2015. Geografía de la Gobernanza. Dinámicas multiescalares de los procesos económicos y ambientales. México: UAM-IZ y Siglo XXI.

Roseberry, W. 2014. Antropologías e historias. Ensayos sobre cultura, historia y economía política. México: El Colegio de Michoacán.

Sack, R. (1986). Human Territoriality: its theory and history. Cambridge: Cambridge University Press.

Santos, M. 2013. Por uma outra globalizaçao. Do pensamiento único à consciência universal. Río de Janeiro: Record.

Tobío, O. 2012. Teritorios de la incertidumbre. Apuntes para una geografía social. Buenos Aires: Universidad Nacional San Martín.

Walker, P. 2017. Nuevas comunas para la región de Aysén. http://www.senado.cl/nuevas-comunas-para-la-region-de aysen/ prontus_senado/2017-06-09/111210.html

Wong-González, P. 2010. Ordenamiento ecológico y ordenamiento territorial: retos para la gestión del desarrollo regional sustentable en el siglo XXI. Estudios Sociales, $\mathrm{N}^{\circ} 1$ Especial, enero, 2010, pp. 10-39. 
